\title{
La filosofía relacional de Andrés Ortiz-Osés
}

\section{The Relational Philosophy of Andrés Ortiz-Osés}

\author{
EDICKSON MINAYA \\ UNIVERSIDAD AUTÓNOMA DE SANTO DOMINGO
}

Recibido: 04/02/2020 Aceptado:12/05/2020

\section{RESUMEN}

Se interpreta el pensamiento hermenéutico del filósofo aragonés Andrés Ortiz-Osés como una filosofía relacional. Por destacar el carácter mediador de la realidad, en tanto construcción de sentido gracias al lenguaje y la experiencia interhumana. Se comprende, además, las características de esta reflexión ontológica, muy apegada a las consecuencias de la crisis de la metafísica tradicional y al impulso de la filosofía hermenéutica. En atención a esto, el pensamiento ortizosesiano intenta superar los dualismos y monismos heredados, para anteponer la relación entre ser humano, mundo y lenguaje. El objetivo: una tercera vía ontológica llamada implicacionismo o relacionismo.

\section{PALABRAS CLAVE \\ HERMENÉUTICA SIMBÓLICA, FILOSOFÍA RELACIONAL, IMPLICACIONISMO, SENTIDO, SÍMBOLO}

\begin{abstract}
The hermeneutical thinking of the Aragonese philosopher Andrés Ortiz-Osés is interpreted as a relational philosophy. Philosophy that highlights the mediating nature of reality, as a construction of meaning thanks to language and interhuman experience. It also includes the characteristics of this ontological reflection, very attached to the consequences of the crisis of traditional metaphysics and the impulse of hermeneutical philosophy. In view of this, ortizosesiano thought tries to overcome inherited dualisms and monism's, to put the relationship between human being, world and language. The objective: a third ontological pathway called implicationism or relationships. KEYWORDS

SYMBOLIC HERMENEUTICS, RELATIONAL PHILOSOPHY, IMPLICATIONISM, SENSE, SYMBOL
\end{abstract}

(C) Contrastes. Revista Internacional de Filosofía, vol. XXV N²2 (2020), pp. 119-136. ISSN: 1136-4076 Departamento de Filosofía, Universidad de Málaga, Facultad de Filosofía y Letras Campus de Teatinos, E-29071 Málaga (España) 


\section{HERMENÉUTICA SIMBÓLICA Y ONTOLOGÍA}

El FILÓSOFO ESPAÑOL ANDRÉS ORTIZ-OsÉS (1943) ocupa un lugar prominente en el pensamiento español de los últimos treinta años del siglo XX y lo que va del XXI. Pero, además, en el panorama universal de la hermenéutica se le podría considerar como un auténtico colaborador de su desarrollo; a parte de sus contribuciones a la cultura filosófica global: promotor de ediciones, traducciones, revistas y diccionarios. ${ }^{1}$

Luis Garagalza (2011, p.14) señala tres características principales de su propuesta: a) su interpretación simbólica de las categorías abstractas de la metafísica tradicional; b) su viveza y riqueza lingüística y c) su apertura existencial que convoca a un diálogo permanente con diversos filósofos o tradiciones. Con todo esto, la filosofía de Andrés Ortiz-Osés propone una hermenéutica simbólica y una concepción de la realidad que él denomina «implicacionismo» $\mathrm{u}$ «ontología de la implicación», aunque algunos de sus comentaristas han preferido hablar de «implicacionismo simbólico» como es el caso de Marta Herrero Gil (2011, pp.49-51) o Ibon Zubiaur (2011, pp.17-20) que sugiere múltiples nombres como los de «filosofía de la co-implicación», «filosofía de la razón afectiva», «dualéctica coimplicativa». Como fuese, su pensamiento es testigo de nuestro tiempo: dialoga con la hermenéutica de Gadamer, Ricoeur, Coreth, Vattimo; además con las filosofías de Nietzsche, Cassirer, Heidegger, Amor Ruibal y la psicología de Jung. Guerenabarrena ha sabido valorar la propuesta de Ortiz-Osés diciendo:

La filosofía hermenéutica de Andrés Ortiz-Osés se configura en un momento histórico decisivo dentro del panorama filosófico europeo. Es hija de su tiempo. El tiempo, en el corpus ortizosesiano, ejerce una labor estructurante, tanto en su vertiente asimiladora de la tradición, como en su momento presente de aplicación metodológica. Asimismo, el tiempo despliega su virtualidad futura, en la forma de un proyecto de filosofía integradora (implicacionista) (2008, p.307).

Desde esta «actividad integradora» se construye una concepción de la realidad entendida como «sistema de relaciones», asumiendo la categoría de símbolo y «urdimbre de sentido» como ejes fundamentales de la experiencia humana. El símbolo se entiende aquí como el intermediario de una realidad

1 Es importante destacar que Ortiz-Osés fue de los primeros en introducir la hermenéutica en España. Esto le condujo a motivar la traducción del libro Verdad y método de Gadamer en la editorial Sígueme de Salamanca. Ortiz-Osés ha colaborado con la editorial Anthropos y en la misma editorial Sígueme. Todo esto sin contar con grandes aportes como el Diccionario de Hermenéutica que cuenta con varias ediciones. 
no objetiva y no dogmática, pero si ligada a lo afectivo; al «corazón» diríamos en terminología romántica.

Esta filosofía reclama la recuperación del simbolismo humano como portador de un sentido latente que ayuda a explicar la naturaleza de nuestra psique, ligada a la cultura. Por eso defiende la dimensión antropológica por encima de la metafísica, por ser capaz de hablar del hombre y su mundo en un lenguaje que se sustrae a cualquier abstracción incomprensible.

A partir de su óptica personal, Osés comprende la realidad como un «gran texto» que teje significados y sentidos. La realidad -dice- es una «red o tejido relacional que configura diferentes urdimbres, estructuras y tramas» (Ortiz-Osés 1999, p.100). Este planteamiento asume la primacía de la «interpretación» como actividad fundamental en la construcción del conocimiento, provocando un importante cambio en la noción clásica de realidad asumida como «dato» $\mathrm{u}$ «hecho puro». Por el contrario, la concepción ortizosesiana presenta la realidad como el resultado de una producción del sentido. A esta visión el autor también la llama «dualéctica», pues «trata de coimplicar los contrarios manteniéndolos en su relacionalidad y ambivalencia mutua, en su correlatividad y complicidad», nos dice Luis Garagalza (2011, p.13).

Para Osés la filosofía deviene en reflexión sobre el sentido, o bien «sobre la textura o contextura de la realidad omnímoda» (Ortiz-Osés 1999, p.100) en tanto es implicación o relacionalidad de lo real con el sentido vivido; y la hermenéutica simbólica, en cuanto filosofía primera, sería un intento de explicar la totalidad de este sentido como proyección simbólica (Garagalza 2011, p.14).

En este debate Ortiz-Osés funda una concepción implicacionista de las cosas. Significa que existe una «textura constitutiva y relacional» del mundo; luego, la filosofía sería ese «texto» encargado de re-cogerla y darle unidad a partir de sus relaciones; de otorgar sentido a esas relaciones que vienen tejidas, y que son preexistentes a la conciencia o existencia. La filosofía, entonces, ocupa un «lugar inter-medial» ya que media la comprensión de nuestras relaciones con el mundo. La filosofía se convierte en «razón dialógica», pues entabla un diálogo entre ser humano y mundo al encuentro.

\section{SU IDEA DE HERMENÉUTICA}

Desde un marco general, Ortiz-Osés concibe la hermenéutica como la reflexión filosófica en torno a la experiencia de la interpretación y comprensión. Lleva a cabo una crítica de nuestro humano entender, proponiendo modelos metodológicos que ayuden a la captación del sentido producido desde cualquier ámbito de nuestra praxis; es decir, la hermenéutica se constituye en una reflexión sobre la actividad de la interpretación, pero que no se reduce 
al significado de los textos, sino que alcanza un «más allá» de lo escrito para situarse en la estructura de la comprensión humana. A partir de este objetivo la hermenéutica desarrollará una experiencia que trasciende los límites que impone el canon de las ciencias, retomando la «apertura al mundo» que provoca la historia, la tradición, el lenguaje y los sistemas simbólicos.

Por eso, Ortiz-Osés entiende que la hermenéutica ha de plantearse el «entendimiento» entre los seres humanos en el contexto de la cultura, los valores democráticos y la productividad del sentido. Es entonces cuando su hermenéutica aparece como una «antropología fundamental» (antropología filosófica) y como una filosofía del lenguaje. Labor que lleva a cabo en su etapa inicial de trabajo a partir de tres obras: Antropología hermenéutica de 1973, Mundo, hombre y lenguaje crítico de 1976 y Comunicación y experiencia interhumana de 1977. Esta labor no se acaba en estos textos, sino que se extiende por más de treinta años con libros como El inconsciente colectivo vasco de 1982, La nueva filosofía hermenéutica de 1986 o su contundente obra ontológica Metafisica del sentido de 1989 u otra más antropológica y biográfica como Las claves simbólicas de nuestra cultura: matriarcalismo, patriarcalismo, fratriarcalismo de 1993; sin olvidar otras como Visiones del mundo de 1995, Cuestiones fronterizas de 1999; o también aquellas entrando el segundo milenio como La razón afectiva del 2000, Amor y sentido del 2003. Sin hablar de su trabajo aforístico, o creación/participación de diccionarios filosóficos y hermenéuticos.

En todas ellas, el lenguaje humano tiene una función central sin privilegiar una única dimensión del «signo lingüístico», sino que las dimensiones sintáctica, semántica y pragmática del lenguaje quedan integradas o implicadas. De esta forma, la hermenéutica atañe a la totalidad de nuestro acceso al mundo desde el lenguaje, cuyo objetivo central es el entendimiento de las cosas y el mundo, fundando a su vez, un «interlenguaje dialógico», democrático y relacionista (Garagalza, 2011, p.14) que hace del pensamiento filosófico de Andrés OrtizOsés «inmune a la esclerosis del concepto abstracto» (Zubiaur 2011, p.17).

En la hermenéutica simbólica ortizosesiana se recupera el «diálogo crítico» con la tradición y se funda un «sentido común ilustrado» que propone a la interpretación como el modo específico del ser humano para construir conocimiento. Es decir, el conocimiento es interpretación ligado a la dimensión lingüística, entendida aquí como la originaria mediadora de nuestro entendimiento.

Pero la propuesta del filósofo se extiende «más allá» de estas indicaciones, pues, en él la hermenéutica se convierte en una «teoría generalizada de la interpretación» y de los lenguajes simbólicos. En este horizonte, su empeño 
desarrolla tres dimensiones teórico-prácticas que invitan atender a lo profundo e incitan al pensamiento creativo:

a) Una concepción del lenguaje y la interpretación como centros del entendimiento humano, en la que el símbolo juega un papel importante en la construcción de las «Weltanschauungen» en tanto proyectan los ideales y valores (simbólicos) de cada individuo o cultura (Ortiz-Osés, 1995).

b) Una antropología fundamental, donde se plantea la relación hombre-lenguaje, lenguaje-mundo (Ortiz-Osés, 1973, 1976).

c) Intento por crear modelos hermenéuticos que ayuden a la praxis interpretativa y comprensiva de la cultura desde su dimensión simbólica (Ortiz-Osés, 1989, 1993, 1996, 2000, 2003).

Para lograr este proyecto, el autor asume una actitud interdisciplinar, acogiendo a las ciencias humanas como ámbito de comprensión de las distintas dimensiones del ser humano y sus límites. Por esta razón, Ortiz-Osés se propone la «fundación de un interlenguaje crítico o lenguaje dialéctico» que exponga los problemas estudiados en un sistema o cuadro de relaciones. En ellos quedan articulados «hombre-cultura-lenguaje», presentados en una continuidad que enfrenta cualquier fragmentación o cualquier estereotipo formalista aplicado forzosamente para comprender al hombre. No sin razón, el Editorial que encabeza el volumen No. 57 del Suplemento Anthropos de 1985 dedicado al filósofo, afirma que «su obra es un enorme esfuerzo nadificador de estructuras escleróticas, muertas y hediondas de la cultura estatal» (p.2).

Nos parece que este juicio sintetiza todo el esfuerzo de Ortiz-Osés. Expresa la intención de su hermenéutica simbólica consistente en socavar el fundamento ya deteriorado de la cultura a nivel global y del pensamiento filosófico en particular; sin embargo, la intención de «disolver» no excluye su capacidad por construir una nueva mirada filosófica en torno al ser humano y sus tradiciones. Por el contrario, perforar el subsuelo de la cultura para mejorarla, es lo que aspira su apuesta filosófica.

Según su hermenéutica, el entendimiento y la realidad están relacionados a la producción y actividad simbólica. Desde su perspectiva, «lo dado» al hombre le viene «cocido», ya «masticado» y en muchas ocasiones «tragado» o «diluido». El papel de la hermenéutica simbólica es ayudar a comprender este «suelo implícito» y tácito por formar parte de la experiencia del mundo y la construcción del sentido. Una vez que se sacan a flote estas estructuras ocurre un ensanchamiento de nuestra comprensión, por el hecho de ayudar a integrar los contenidos interpretados a la propia visión. 


\section{RAZÓN AFECTIVA VS RAZÓN ABSTRACTA}

El discurso y la escritura de Andrés Ortiz-Osés se sitúan en la necesidad de «apalabrar» la realidad, de colocar en su lugar el sentido que le pertenece a cada significado interpretado, o bien de dar sentido a lo que en el momento no lo tiene: «Su reflexión, -dice el Editorial mencionado- por ello, es laberíntica, pluridimensional, integradora y alquímica» (p.2). Laberíntica en la medida en que su pensamiento se sumerge en la complejidad de «lo real», yendo y viniendo de un lugar a otro, profundizando en las estructuras de lo simbólico implícitas en las realidades culturales. Pluridimensional, porque está abierta a varias disciplinas filosóficas, a varios autores y textos, a varias tramas de significados, en fin, porque construye un intertexto cultural que posibilita la comprensión de nuestro mundo. Integradora por su capacidad de relacionar, de interconectar, de abrir nuevas interpretaciones. Alquímica, por su habilidad de mezclar y transformar sentidos y significados, además de aplicarlos a nuestra situación actual.

Según Juventino Caminero este «aspecto dialéctico» de su obra tiene que tomarse en cuenta como «uno de los rasgos estructurantes» de su hermenéutica. Este rasgo dialéctico puede resumirse siguiendo las observaciones del mismo Caminero:

[L]os textos de Ortiz-Osés conforman por regla general un discurso en perpetua expansión, constituida formalmente por la combinación de formulaciones anafóricas cognitivas (relaciones lógicas de identidad entre dos términos del discurso, 'pura natura: mundo', 'pura cultura: hombre') y formulaciones anafóricas semánticas (en las cuales la relación es de equivalencia y la identidad sémica evocada es tan sólo parcial); debo añadir, en este sentido, que como hermeneuta su originalidad radica en esto segundo, que es lo que verdaderamente expande el discurso y le da una nueva proyección hermenéutica, traduciendo y consensualizando, si se me permite la paráfrasis. El texto dialéctico, en dos palabras, avanza por condensación conceptual y expansión simbólico-analógica (1985, p.142).

Gracias a esta estrategia metodológica, Ortiz-Osés rompe con la inmediatez del signo convencional ante la riqueza del símbolo, de la realidad y la cultura. Su hermenéutica impulsa y revive el sentido simbólico y metafórico del mundo, del pensamiento y la filosofía. En esta perspectiva, «toda la experiencia está para ser de nuevo re-creada, asimilada y proyectada» (Editorial, p.2). Junto a esto, si tomamos en cuenta las dimensiones epistemológicas y metodológicas de su hermenéutica simbólica, los resultados serían:

1. Marcada recreación del lenguaje que hacen de sus textos «densos y acumulativos». En efecto, en la obra de Ortiz-Osés existe un interés por 
profundizar en las estructuras semánticas de los conceptos empleados, procediendo por acumulación del sentido. O sea, que «cada palabra es un mundo experiencial» (Editorial, p.2). Un espacio por descubrir. Una noción que nos abre a un mundo de significados. Y en esta recreación del lenguaje lo que se busca y encuentra es «su memoria mitológica y simbólica», un registro prístino que permanece invisible e incomunicado. La misión de su hermenéutica simbólica es hacerlo «aparecer», hacerlo resurgir de las «cenizas» de la cotidianidad.

2. La persistencia del enfoque antropológico. La mirada antropológica se revela en su filosofía, en su hermenéutica simbólica. Para Osés el ser es también cultural y no sólo metafísico. El ser tiene rasgos antropológicos y no tan sólo ontológicos, pues, «la cultura es la casa y cita del ser» y no sólo el lenguaje.

3. La necesidad de reconstruir una hermenéutica antropológica y simbólica de la cultura. Razón por la que conviene impulsar el diálogo con «el otro» y «lo diferente» como remedio contra la represión de las culturas dominantes que se afanan por el control del hombre y el mundo. La cultura es lenguaje, es ser, realidad, valores simbólicos.

Por todo ello, la hermenéutica simbólica ortizosesiana reclama una «razón afectiva» frente a una «razón abstracta». La primera atiende al valor de las pasiones, lo emocional como formando parte de la estructura general del ser humano y sus capacidades cognoscitivas, mientras que la segunda sólo atiende al aspecto racional y calculador de las capacidades humanas. Esquemáticamente estas diferenciaciones se pueden representar así:

\begin{tabular}{|c|c|}
\hline RAZÓN AFECTIVA & RAZÓN ABSTRACTA \\
\hline Romántica-Posmoderna & Clásica-Moderna \\
\hline Periférica-descentrada & Logocéntrica \\
\hline Pasional & Racional \\
\hline Interpretativa & Substantiva \\
\hline Material & Formal \\
\hline
\end{tabular}

Desde un punto de vista semántico, una RAZÓN AFECTIVA se funda en conceptos como el consentimiento, la coligación, la aferencia, la encarnadura del espíritu, el sentido, el sujeto-intérprete, la mediación intersubjetiva, la comunicación anímica, lo interpersonal. Mientras que una RAZÓN ABSTRACTA valora el raciocinio, la capacidad de juicio, la cordura, la evidencia, la certidumbre, lo formal, lo abstracto, lo matemático, el cálculo, 
lo lógico, el solipsismo, lo absoluto, la comunicación interior, lo impersonal como característica de la verdad, lo individual.

De este modo, el concepto de «razón clásica» empleado por Ortiz-Osés, viene a significar aquella concepción que plantea el ideal de una razón que se auto-funda en sí misma (en la mente, en el espíritu o la conciencia) y que pretende ajustarse a una supuesta «ley» que le es natural al pensamiento humano. De ahí, que Ortiz-Osés la considere «abstracta» y «desligada» de la vida. O bien, separada del lenguaje, de la existencia y de los afectos o las pasiones humanas. La razón no existe «afuera» de la condición humana, sino inmersa en ella.

A la sazón, nuestro autor descubre una continuidad histórica en la formación y construcción de este ideal de racionalidad abstracta que va de Aristóteles hasta Hegel, aproximadamente (Ortiz-Osés 2000, pp.17-21). Según él, dicho modelo se funda bajo el prototipo de una «conciencia pura». Como consecuencias, se construye una noción de razón completamente desligada de la vida, léase separada de «lo afectivo». Por el contrario, la hermenéutica simbólica ortizosesiana se plantea volver a encontrar el núcleo de lo afectivo vinculado a la inteligencia humana. De ahí, su valoración de la «actividad imaginante» $\mathrm{y}$ creadora como dispositivos constructores de sentido y significado.

Frente a un «heroísmo de la razón pura/puritana» plantea una «razón simbólica» en tanto «razón afectiva y aferente» y por extensión, una «razón adhesiva y adherente, razón implicada e implicante, razón afectada y aficiente» (Ortiz-Osés 2000, p.17). Asimismo, esta razón es "cromática y colorista» (2000,p.18; cf. Ortiz-Osés 1989, pp.101-112). Con este planteamiento, nuestro autor hereda la crítica nietzscheana al ideal clásico de la razón. Pero no sólo se recupera el sentido nietzscheano de la vida, sino también la importancia que tienen la sensibilidad y los sentimientos en la configuración de nuestro pensamiento lógico (Ortiz-Osés 2015). Posicionamiento que continúa una larga tradición en filosofía que arranca con el filósofo francés Blaise Pascal. Se pondera, además, una «interpretación axiológica de la realidad» en la que se resalta la «interpretación del sentido existencial» (Ortiz-Osés, 2000, p.19). Por eso, no es de extrañar el papel que juegan el «sentimiento íntimo» y la «conexión profunda» con las cosas en su concepción del ser humano, aspectos que poseen significados simbólicos.

En virtud de esto, la hermenéutica simbólica viene a situarse entre dos líneas de pensamientos, cuyo punto de intersección es la filosofía de las formas simbólicas de Ernst Cassirer. Ambos horizontes quedarían delimitados así: por un lado, un «romanticismo tragicómico» (Ortiz-Osés 2008); por el otro, un «posmodernismo axiológico» (1986). Desde esta aventura filosófica, 
su hermenéutica atenderá cuatro ámbitos distintos para alcanzar una correcta aplicación de su propuesta: el arte, la religión, la cultura, el mito ${ }^{2}$.

\section{IV. ÁMBITOS DEL SENTIDO: GIRO LINGÜÍSTICO Y GIRO ANTROPOLÓGICO}

Estos cuatro ámbitos son «ámbitos de sentido», que están subordinados a la totalidad de la experiencia humana, ámbitos de imaginación y creación, ámbitos donde se manifiesta el sentido del hombre en su haber; espacios de construcción de significados que empapan y llenan la vida de valor pero que representan, para la filosofía relacional de Osés, espacios simbólicos donde acaecen el ser y la verdad. A partir de la interpretación de estos «ámbitos de sentido», la posición de Ortiz-Osés se va definiendo como el paso o la transición de una hermenéutica del «lenguaje objetual» a una hermenéutica del «lenguaje simbólico». De tal modo, que la hermenéutica simbólica apuesta por la comprensión del sentido, asumido desde su implicación con lo afectivo. Así, el sentido no es una «cosa», es algo más: dice mi condición y dirección en el mundo; mi transformación o cambio como sujeto en la trayectoria existencial; en fin, el sentido canaliza mis pretensiones desde la praxis creadora.

Esto lleva a resaltar el «giro antropológico» como una característica fundamental de la hermenéutica ortizosesiana, de la que también forma parte el «giro lingüístico». Estos giros constituyen el fondo en el que se mueve la hermenéutica simbólica. Pero notamos que al destacar la dimensión antropológica queda desplazada, en cierto grado, la semiológica, que está más preocupada por el problema de la «significación objetiva»; por el contrario, en Ortiz-Osés se subraya el sentido, por cuanto expresa la dimensión afectiva ligada a lo gnoseológico ${ }^{3}$.

Desde este posicionamiento discursivo, la hermenéutica simbólica nos ofrece «esquemas axiológicos y claves de interpretación que posibilitan la comprensión (humana) del mundo» (Ortiz-Osés 2000, p.19). Y es que en sí misma la realidad se expresa en «coágulos de sentido» y «nudos de significación». Ambas metáforas son importantes porque nos ayuda entender la forma en que se constituye la realidad, según esta ontología.

Conviene detenernos en este último punto. Según el DRAE, un «coágulo» es una masa extraída de un líquido; en el contexto de la «ontología de la

2 Ortiz-Osés es uno de autores más conocidos en la interpretación de la mitología vasca, sobre todo sus estudios en torno a la Diosa Mari. Muchas veces «mal interpretado» con «ontologizar» el mito cuando de lo que verdaderamente hace es escudriñar en su identidad narrativa y sentido.

3 Ya hemos aclarado que «razón afectiva» indica esa complementariedad entre pasión y conocimiento; entre voluntad y saber. 
implicación» la «masa» o «coágulo» representaría el sentido y el «líquido» la realidad; la realidad, como lo plantea Ortiz-Osés, deviene en «líquido» que constituye formaciones o masas de sentidos; es decir, se da una verdadera «solidificación» del sentido gracias a la experiencia vivida junto al acto de valorar el mundo. El «órgano» por excelencia que permite aglutinar, amasar nuestro encuentro con el mundo es la interpretación. Ella, junto a la «razón afectiva», se transfigura en una «razón simbólica» que Osés interpreta también como razón «que pasa de la aguerrida visión fundamental/fundamentalista del mundo a una visión relacional y coimplicacional del sentido» (Ortiz-Osés 2000, p.20).

Esta actitud ontológica realiza una «nueva» síntesis entre hermenéutica y simbolismo (Ortiz-Osés 2000, p.76), síntesis que han podido confirmar discípulos suyos como Luis Garagalza (2009), Blanca Solares (2002), Patxi Lanceros (1993), entre otros. Ellos coinciden en que, para realizar el paso a lo simbólico, el autor parte de la «función relacional del lenguaje». Es decir, el lenguaje dice o relata (la relación) en tanto es capaz de tejer el sentido o el significado de las cosas. Ahora entendemos lo que quiere decir Ortiz-Osés cuando afirma:

A mi entender el lenguaje no dice pura inmanencia lingüística, sino que dice relación existencial y, por tanto, apertura al otro (comunicación). Pero un tal lenguaje relacional es un lenguaje-relato, en cuanto narración de las relaciones humanas en un contexto no meramente semiótico o semiológico sino mitosimbólico. $\mathrm{O}$ el lenguaje como relato del alma y sus avatares de sentido (Ortiz-Osés 2000, p.77).

Por tanto, nuestro filósofo se acoge a una concepción más pragmática del lenguaje que puramente formal o lógica (aunque tampoco se obvia esta dimensión), superando la reificación del alma en vía de recuperar el simbolismo que se expresa en las creaciones humanas. Siguiendo este hilo conductor, repetimos, la hermenéutica simbólica ortizosesiana sigue esa línea abierta por Pascal que pretende romper con una concepción absolutista de la razón, para dar el paso hacia una «razón sentimental». Esto es, una «razón con corazón» en tanto es «co-razón»: razón compartida que se nutre del otro y con lo otro (Cf. Ortiz-Osés 2003a).

Con esto la hermenéutica simbólica pone crisis el viejo dogma de la metafísica clásica y moderna en torno a la realidad concebida bajo el esquema de la «substancia», «lo entitativo» o la «esencia». Pero, como bien afirma Garagalza (2014 p.293), el pensamiento filosófico de Andrés Ortiz-Osés al suscribirse a una filosofía del sentido cuestionará aquella concepción por ser limitada y cerrada, y nos muestra cómo la realidad es un tejido contenedor de lo implícito (el símbolo) y lo explícito (el signo). Así, la realidad no se muestra 
como una superficie lisa, sino que aparece como corrugada, agrietada; con protuberancias y fisuras. Igualmente, la «ontología implicacionista» necesita instituir un nuevo lenguaje ontológico capaz de comprenderla en su ser; pero más que acudir a las categorías de sustancia, esencia y permanencia para caracterizar o «describir» «lo real», Ortiz-Osés recurre a conceptos como «urdimbre», «texto», «intertexto», «relación», «implicación», «correlación»... llegando a una cosmovisión que retoma el problema de la realidad integrada al ser cultural y a la creación simbólica; asumiendo el giro antropológico de la filosofía, en la medida en que la ontología que se busca efectúa «una vuelta de las cosas al mundo del hombre caracterizado por el lenguaje y la interpretación» (Ortiz-Osés 2000, p.73). Esto quiere indicar que las cosas del mundo están afectadas por el hombre, en tanto le da valor mediante un acto productor de sentido que requiere de la comunicación y el lenguaje para materializarse; sin embargo, esta vuelta no significa hacer del hombre el centro del mundo, como el viejo antropocentrismo renacentista. Todo lo contrario, «Volver al hombre significa recuperar la finitud y la contingencia humanas de nuestros logros, enmarcándolos en un horizonte cohabitado por el tiempo» (p.73).

En esta filosofía, la categoría de «contingencia» adquiere valor más allá de la concebida por la metafísica tradicional, que la plantea por debajo de la «esencia». Al recuperar su riqueza ontológica, Osés nos recuerda que «contingencia» viene de «acontecer». Es decir, el ser humano, lo real o el mundo acontecen, se dan, se manifiestan; lo cual significa que pueden suceder o no, ser algo o no serlo. Es así como el «acontecimiento» funge también como «dirección de lo sentido»; como lo vivido desde mis sentimientos, mis afecciones, mi lugar en el mundo.

En este caso, el papel de la relación es ser mediación en sí misma, posibilitando la mezcla de las cosas en tanto acontecen. Por ejemplo, un huevo, una simple planta, aparecen como mezcla de lo material y sus atributos; la forma y su textura, que podría separarse sin que tengamos que desmembrar su realidad. O sea, la realidad «planta» está ligada, relacionada a la de verdor, hojas, raíces, alimentos, etc. Esto significa que «Relación y relacionismo no flotan abstractamente en el espacio puro o incontaminado, sino que interpenetran la realidad y (re)median las realidades» (Ortiz-Osés 2000, p.87). Por eso, se coloca «la relación y el relacionismo sobre el basamento matricial de los elementos: la relación es siempre relación de los elementos, de modo que el relacionismo reaparece como ontorelacionismo o relacionismo elementar (radical/radicado)» (p.87).

Entonces, el ser no es simplemente el ser, sino «ser relacional». Es decir, el ser no flota abstractamente, sino que de por sí se encuentra relacionado, abierto a lo otro y no ensimismado: 
[E]l carácter específico de un tal ser radicaría entonces en la(in)serencia, vocablo con el que queremos mentar la inserción del ser en los seres, de forma que no cabe hablar de diferencia absoluta entre el ser y los seres... sino de diferencia hermenéutica y coimplicación ontológica. (El) ser en efecto se insiere o inserta en los seres a través de la esencia (Ortiz-Osés 2000, p.89).

En ese sentido, para la filosofía ortizosesiana el logos «re-une» (vuelve a unir) realidad e idealidad. El logos se encarna en el ser humano y lo hace hablar desde su sí mismo. Por lo que el lenguaje dice «lenguaje-relato»; «lenguaje relator» y delator de las particularidades o peculiaridades del ser de lo real; mientras que el hombre se considera como un «ser-relatado» por el logos. Entonces, es cuando el lenguaje se convierte en «la conjunción antropológica de idealidad y realidad» $(2000$, p.92). O lo que es lo mismo, lo imaginario y lo real coexisten; en ellos se da una originaria correlación, ya que «lo real» se encuentra implicado en la «acción imaginante». Y así, «el lenguaje se expresa complementariamente de un modo subjetivo-objetivo por cuanto se parte del propio sujeto o subjetividad al objeto u objetividad» (p.92). Por esa razón, la realidad dice relación. Todo sentido es relacional en sí mismo y está encarnado en lo material y cognitivo: en la materia y la razón.

\section{CONCLUSIÓN: ONTOLOGÍA IMPLICACIONISTA. REALIDAD Y CONOIMIENTO}

Hasta aquí el problema de la realidad para la ontología implicacionista de Ortiz-Osés. Pero ¿qué pasa con el conocimiento de ella?

Ante todo, es importante subrayar que el autor asume un «perspectivismo» respecto al conocimiento. Posición que supone lo siguiente:

a) Que el conocimiento se construye a partir de «datos», pero que la conciencia, la imaginación, la capacidad simbolizadora y metafórica de la mente participan activamente en su formación. De ahí el «elemento subjetivo» o «personal» de todo conocimiento. Este componente no aparta la realidad. Lo que quiere decir es que el conocimiento depende de la actividad creadora del sujeto y su capacidad de innovar.

b) Que somos seres finitos y carenciales, y por eso conocemos en perspectiva; por tanto, lo que conocemos de la realidad es una dimensión y nunca la totalidad de modo absoluto. Esto significa que estamos abiertos a la posibilidad de conocer otras relaciones o caras de la realidad.

c) A partir de aquí «La realidad en su ser deja de definirse en formas absolutas, pero sin recaer en el relativismo: la realidad radical en su ser dice relación fundacional de sentido» (Ortiz-Osés 2000, p.95). O lo que es lo mismo, el conocimiento funda una perspectiva a la vez que se parte de una para construirlo; el conocimiento es un criterio 
que enriquece el sentido común convirtiéndolo en «sentido común crítico» e ilustrado.

La relación aparece como red invisible, como «principio de fundación de la realidad»y de lo real ( $c f$. Ortiz-Osés 2000, pp.96, 98). La relación opera a modo de nexo, enlace; de enclave, contextura; pues asegura el fondo en el que las cosas aparecen. Esta relación queda representada simbólicamente por el amor, por lo afectivo. Esto es, por aquello que enlaza, ata o une (Ortiz-Osés 2003; Zubiaur 2011, p.19). Según Osés, esta concepción «disuelve la continuación del pensamiento clásico del Ser como fundamento antiguo (ontologismo) en la Razón moderna como fundamento racionalista (idealismo): pero también disuelve la presunta absolutez de la relación como categoría sustantiva, ya que la esencia de la relación es su autorrelatividad» (Ortiz-Osés 2000, p.98).

Ahora «lo real» se funda en virtud de un posicionamiento del seren-relación. O sea, que la realidad o lo dado como entidad se basa en las relaciones y no en abstracciones vacías, pues, los «elementos primordiales» que conforman la realidad «sólo [son] concebibles en relación»(2000, p.102); pero los elementos con los que se enlazan también son relativos a otro conjunto. Hay pues, lo que Ruibal llama una «ley de relaciones» basada en ese posicionamiento del ser.

Pero si existe un elemento que por excelencia está revestido de todo un sistema relacional es el símbolo. Para el filósofo el símbolo no se reduce al signo convencional poseedor de «significado objetual», sino que expresa una dimensión de carácter afectivo y emocional. El símbolo logra una conexión espiritual que no encontramos en ninguna señal o signo. Por eso, el simbolismo pertenece a lo cultural, contiene una perspectiva antropológica, además está implicado en todas las esferas del «discurso humano». Asimismo, el símbolo significa el paso de la materia a la imaginación; de ahí su enlace estrecho con la materia, la sensibilidad, la imagen; razón y sentimiento subyace a todo símbolo. Es esta interrelación la que permitirá a la imaginación sus ensoñaciones. El hombre imaginal, es decir en tanto imagina, puede a partir de esta recrear el sentido o crear mundos posibles; haciendo del símbolo su unidad fundamental para representar lo real. En este horizonte, la hermenéutica simbólica se enfrenta a cualquier concepción que pretenda encerrar la razón, obligándola a reprimir lo imaginal o los imaginarios posibles.

En opinión del autor, en el simbolismo subyace la «imaginación creadora»; una cualidad que el ser humano ganó en el largo proceso de su evolución como especie, forjándose un nuevo espacio de libertad y creatividad. De ahí que el simbolismo signifique, por otra parte, la posibilidad de alcanzar otra dimensión de sentido que condensa vivencias y sólo representadas por la imagen simbólica. 
Al centrarse en el símbolo, la hermenéutica de Ortiz-Osés acentúa una concepción del lenguaje que trasciende la idea instrumentalista del mismo, que la entiende como un simple «medio» de comunicación. Por el contrario, el lenguaje según Osés constituye una experiencia del mundo que materializa la expresión; es además, ámbito de creación del sentido y catalizador de las formas simbólicas como el arte, el mito o discursos como el religioso, el filosófico y científico. Por lo tanto, el lenguaje es una forma de vida. El lenguaje constituye una urdimbre fundamental que conecta el mundo, lo social y lo cognitivo con la estructura de la persona.

El simbolismo expresa, pues, un sistema de valores y valoraciones culturales, relacionadas con la vida humana y la realidad; articulando, así, toda una ontología, todo un decir acerca de la realidad. Simbolismo dice, pues, experiencia del valor y comunicación de valores a nivel colectivo. Hay en el símbolo una «sustancia anímica» que le subyace ${ }^{4}$.

Un caso bastante estudiado por Ortiz-Osés es el mito. Para Osés, el mito «señala el origen de nuestra cultura» (2000, p.27), es decir, toda cultura, y no sólo la occidental, «encuentra su origen en el mito», en el sentido de que le subyace una narración simbólica que empieza a dar sentido a nuestro entorno: la naturaleza y la sociedad. De esta forma, gracias al mito, el ser humano empieza a experimentar el mundo desde «su radical vivencia mitoreligiosa» (p.27). El mito aparece como «la experiencia radical del hombre en el mundo por cuanto es la vivencia fundamental de su radicación» (p.27).

Por otra parte, el símbolo articula la relación mito-cultura-sociedad en una especie de continuo que acompaña al hombre en sus avatares existenciales. Luego, en la medida en que avanza las preocupaciones de Osés en los años ochenta, empieza a tener una mayor preocupación por lo simbólico, y a nuestro juicio verá en la mitología vasca un suelo importante donde comenzar nuevamente. Aunque en su obra de 1977 dejaba claro ese interés, no es hasta la introducción del debate matriarcalismo/patriarcalismo a inicios de los ochenta que dicha decisión teorético-práctica empieza a cobrar fuerza, cuando asume una lectura simbólica de la historia de la cultura occidental, lectura que creemos está motivada por el redescubrimiento de lo vasco a través de sus mitos y tradiciones.

Esto le lleva a considerar el lenguaje simbólico como un artilugio del pensamiento humano por querer decir el sentido. Un sentido latente y existencial: «De este modo, el lenguaje pasa a primer plano como

4 «Sustancia anímica» dice: capacidad de canalizar la vida, es materia en movimiento; impulsora de acciones capaces de dar valor y sentido. Así, el símbolo es capaz de canalizar un sentido vivido pero oculto en la imagen. 
estructura dialógica depositaria de la experiencia interpretativa (cultura) en forma simbólica» (Guerenabarrena 2008, p.310). Y Osés ve en los mitos la manifestación del lenguaje simbólico que expresa toda una cosmovision del mundo. De ahí que el énfasis en el carácter simbólico o figurado del lenguaje le conduce a tener que desentrañar estructuras psicosociales, donde «la lingüisticidad se transforma en simbolicidad» (Guerenabarrena, p.311).

Sin embargo, creemos que Osés no busca sólo explicar los contenidos simbólicos de la mitología vasca, sino justificar el sentido cultural de «lo vasco» en el macro-contexto de la cultura europea. Todo esto, pensamos, conlleva una actitud política no partidaria, sino franca, democrática y en forma de respeto por la diversidad cultural, y el concepto más adecuado para expresarla es el concepto de «fratriarcalismo».

«Fratriarcalismo» es una noción que resguarda un ideal de convivencia a manera no utópica, aunque cargado de sentido posible frente a la crisis global que estamos experimentando. En su libro El Dios heterodoxo. Los demonios de nuestra cultura (2014a) arrogaba el ideal de la «auténtica democracia» a propósito de la crisis económica española; asumiendo una crítica política nos dice: «Para sobreponernos a nuestro descrédito democrático necesitamos pasar de lo particular o individual a lo común o comunitario, de las cofradías al fratriarcado, de las germanías a la hermandad, de las fratrías a la Fratria como hermandad universal (unidiversal)» (Ortiz-Osés 2014a, p.7). Como podemos notar, se trata de un pensamiento que piensa la globalización y sus peligros. Pero también, un posicionamiento filosófico capaz de reflexionar realidades locales. Esas que afectan a la convivencia española.

En definitiva, estamos de acuerdo con Patxi Lanceros al sostener que toda la obra de Ortiz-Osés tiene a la mediación como objetivo fundamental (Lanceros 2011, p.240); su pensamiento desarrolla un ejercicio de implicación donde se trazan fronteras, se tienden puentes, se piensan mediaciones, se eliminan escollos y se arriba al intento de tejer experiencia y conciencia; así, lo personal-biográfico con lo académico y especializado. Por lo tanto, toda la obra de Ortiz-Osés es un diálogo enriquecedor de pensamientos e ideas.

Replantear el concepto de razón y el de racionalidad humana, ha sido una constante en la hermenéutica simbólica de Ortiz-Osés. Esto le permite, incluso, mantener distancia del proyecto de la modernidad; pero también a tener una conciencia crítica de la posmodernidad. Tres grandes obras le permitieron fortalecer esta visión: La nueva filosofía hermenéutica (1986), Metafísica del sentido (1989) y La razón afectiva (2000). Desde ellas inaugura su concepción antiheroica de la razón y empieza a considerar una razón cargada de afectos; una «razón sentimental», afectiva. Una razón como «co-razón» (2003b).

En ese mismo sentido, «el autor desecha tanto el absolutismo de la razón y la verdad, como su relativismo típicamente posmoderno, considerando el 
sentido como un 'relaciocinio' en el horizonte de un relacionamiento (en línea con el correlacionismo de Amor Ruibal)» (Garagalza, 2014, p.293). Más que considerar a la razón como «padre», pasa a considerarla como «hermano» de todas las cosas. En efecto, la razón se hermana con el sentimiento, en tanto el hombre es un «ser-afectado» por el mundo, por la cultura y por los «otros».

Pero de lo que en el fondo se trata es de entender el sentido como urdimbre existencial. A tal efecto, pudimos corroborar cómo desde la obra de Ortiz-Osés se considera el sentido, su producción y transmisión como esa membrana que se teje alrededor de la existencia sin la cual no puede subsistir. Justamente, existir es construir y comprender el sentido, tanto de la vida como de las cosas; sin embargo, sentido dice o «co-dice» relación con el mundo y los otros, y participantes de una amplísima red de significados y sentimientos que nutren nuestros proyectos en tanto sumergidos en idealidades.

Si bien es cierto que la obra de Ortiz-Osés marca un nuevo hito en el territorio de la filosofía española, debemos decir que también nos ofrece una nueva dirección en la línea actual de la filosofía hermenéutica. Obra que invita a realizar nuestra propia interpretación del mundo. No sólo consumiendo sus significados, sino además asumiendo -como él mismo dice- un sentido propio.

La obra de Ortiz-Osés es la oportunidad para experimentar otra filosofía del hombre, otra filosofía de la cultura, otra ontología de la interpretación.

\section{REFERENCIAS BIBLIOGRÁFICAS}

CAMINERO, J. 1984: «El idiolecto discursivo-estilístico en la obra del pensador A. Ortiz-Osés», en Letras de Deusto, Vol. 14, No.28, pp.129-158.

GARAGALZA, L. 2009: «Prólogo: Filosofía del sentido», en Ortiz-Osés, A. Heidegger y el ser-sentido. Edición de Luís Garagalza y Javier Martínez Contreras. Bilbao: Universidad de Deusto, Pp.7-10.

GARAGALZA, L. 2011: «Presentación: Sensus -la clave del sentido», en Filosofia, hermenéutica y cultura. Ensayos en honor de Andrés Ortiz-Osés. Deusto: Bilbao, pp.13-16.

GARAGALZA, L. 2014: El sentido de la hermenéutica. La articulación simbólica del mundo. México: Anthropos.

GUERENABARRENA, F. 2008: «Epílogo: la hermenéutica simbólica de Andrés Ortiz Osés», en Ortiz-Osés, A. Meditación del existir. Una revisión del mundo. Zaragoza: Olimar, pp.307-316.

HERRERO GIL, M. 2011: «Teorías del imaginario: entre la ciencia y la mística» en Garagalza, L. (Coord.), Filosofía, hermenéutica y cultura. Ensayos en honor de Andrés Ortiz-Osés. Deusto: Bilbao, pp.37-56.

IBON, Z. 2011: «Obertura: filosofía aforística», en Garagalza, L. (Coord.), Filosofia, hermenéutica y cultura. Ensayos en honor de Andrés Ortiz-Osés. Deusto: Bilbao, pp.17-20. 
LANCEROS, P. 1993: «Presentación: la metafísica ineludible», en Ortiz-Osés, A. Las claves simbólicas de nuestra cultura. Matriarcalismo, patriarcalismo y fratriarcalismo. Barcelona: Anthropos, pp.11-12.

LANCEROS, P. 2011: «Los libros, los años (Itinerarium mentis ad sensum)», en Garagalza, L. (Coord.). Filosofía, hermenéutica y cultura. Ensayos en honor de Andrés Ortiz-Osés. Deusto: Bilbao pp. 239-254.

SOLARES, B. 2002: El Dios andrógino. La hermenéutica simbólica de Andrés OrtizOsés. México: Porrúa. Suplemento Anthropos dedicado a Andrés OrtizOsés. 1986, No.57, Barcelona: Anthropos.

ORTIZ-OSÉS, A. 1973: Antropología hermenéutica. Para una filosofía del lenguaje del hombre actual. Madrid: Ricardo Aguilera.

ORTIZ-OSÉS, A. 1976: Mundo, hombre y lenguaje crítico. Estudios de filosofia hermenéutica. Salamanca: Sígueme.

ORTIZ-OSÉS, A. 1977: Comunicación y experiencia interhumana. Una hermenéutica interdisciplinar para las Ciencias Humanas. Bilbao: Desclée de Brower.

ORTIZ-OSÉS, A. 1982: El inconsciente colectivo vasco. Mitología cultural y arquetipos psicosociales. Deusto: Txertoa.

ORTIZ-OSÉS, A. 1985: Antropología simbólica vasca. Barcelona: Anthropos.

ORTIZ-OSÉS, A. 1986: La nueva filosofía hermenéutica. Hacia una razón axiológica posmoderna. Barcelona: Anthropos.

ORTIZ-OSÉS, A. 1988: El matriarcalismo vasco. Bilbao: Universidad de Deusto.

ORTIZ-OSÉS, A. 1989: Metafísica del sentido. Bilbao: Universidad de Deusto.

ORTIZ-OSÉS, A. 1993: Las claves simbólicas de nuestra cultura: matriarcalismo, patriarcalismo, fratriarcalismo. Barcelona: Anthropos.

ORTIZ-OSÉS, A. 1995: Visiones del mundo. Interpretaciones del sentido. Bilbao: Universidad de Deusto.

ORTIZ-OSÉS, A. 1996: La diosa madre. Interpretación desde la mitología vasca. Madrid: Trotta.

ORTIZ-OSÉS, A. 1999: Cuestiones fronterizas. Una filosofía simbólica. Barcelona: Anthropos.

ORTIZ-OSÉS, A. 2000: La razón afectiva. Arte, religión y cultura. Salamanca: Editorial San Esteban.

ORTIZ-OSÉS, A. 2003a: Amor y sentido. Una hermenéutica simbólica. Barcelona: Anthropos.

ORTIZ-OSÉS, A. 2003b: Co-Razón. El sentido simbólico. Madrid: Kalamos Libros.

ORTIZ-OSÉS, A. 2007: Los mitos vascos. Aproximación hermenéutica. Bilbao: Universidad Deusto.

ORTIZ-OSÉS, A. 2008: La herida romántica. Salir del almario. Barcelona: Anthropos.

ORTIZ-OSÉS, A. 2014: El Dios heterodoxo. Los demonios de nuestra cultura. Zaragoza: Institución «Fernando el católico».

ORTIZ-OSÉS, A. y LANCEROS, P. (Coords.) 1997: Diccionario de Hermenéutica. Bilbao: Universidad Deusto. 
EDICKSON MINAYA es profesor de Filosofía de la Universidad Autónoma de Santo Domingo y actual director del departamento.

Líneas de investigación:

Filosofía hermenéutica, Fenomenología, Teoría de la representación simbólica, Filosofía contemporanea, Metafilosofía.

Publicaciones recientes:

(2020) Simbolismo e implicación. Contribuciones a la hermeneutica simbólica de Andrés Ortiz-Osés. Bogotá: Aula de Humanidades (en edición).

(2018) Ser-en-(la)-relación. Ensayos para una hermenéutica relacionista. Oviedo: Editorial Eikasia.

Correo electrónico: paolo.geminaya45@uasd.edu.do 